\title{
Analysis of Some Very Old Olive Tree
}

\author{
Hairi Ismaili* \\ Genetic Bank, Agricultural University of Tirana, Albania \\ *Corresponding author
}

\section{A B S T R A C T}

\section{Keywords}

Olive tree, Oil,

Tree, Mills,

Ancient objects

Article Info

Accepted:

16 December 2017

Available Online:

10 January 2018
This study deals with the olive and oil paths in the district of Tirana, and has been aimed at promoting domestic tourism as a new opportunity for the economy, culture and history of the country. Some exploratory missions are performed to identify the oldest trees based on the information of the locals, over two basic terms: large trunk biometry, and indigenous Variety. Through an expedition were traced the centuriesold olive groves of Tirana and identified the old tree, mills and other ancient objects. Over 300 old trees have been observed and conform to the terms, of which 35 older trees have been selected, who are over 1.500 years old and are only in Tirana district. Seven individuals are over $2.500-3.000$ years old, i.e. the first millennium BC, and together with the forts symbolize ancient Illyrian culture. As a conclusion, only a part of the objects found have the conditions for promotion because they are an exclusive testimony of ancient cultures of the country.

\section{Introduction}

In Albania there are three ssp. of olive; Olea europaea L. ssp sativa, oleaster and Sylvester's. Different archaeologists say that the first traces of Sylvester's (ssp. sylvestris), are 60,000 years before around the Mediterranean since the last glaciers (Ismaili, et al., 1995).

According to Herodotus's description (Greek historian), Molose peoples (Today Albania South), had good economy, had vineyards and very developed olive. These people deal with the olive tree, the first tree was securing oil... fishing, while part with livestock, (Osmani, 1993); (Cantini et al., 2002). Scymnus (a
Greek geographer) three centuries B.C describes Epirus and Illyria as a warm prosperous country, filled with good olives, orchards, and vineyards (Ismaili, 2010).

The wild olive Domestication in the Mediterranean basin is 40-45 thousand years before and Tukidide says, "That when the Mediterranean peoples began to cultivate olives were separated from barbarity" (Ismaili, et al., 1995); (Loukas et al., 1983). Albania has about one million old trees, which have not been assessed in respect to their age. Often, these trees are under risk of extinction of the reconstructions and other uses. Urbanization of the territory is also an important cause. 
Greek researchers have applied engineering technologies to develop a geometrically accurate 3D age determination model, (Remondino et al., 2009); (Bruno et al., 2010); (Scopigno et al., 2011). Many researchers present old trees and their approximate age, based on opinions, carbon analysis or morphometry of the tree, (Riley, 2002). Some researchers applied Measuring tree stem diameters using intensity profiles from ground-based scanning lidar from a fixed viewpoint, (Lovell, et al., 2011); (Bae, et al., 2008).

In Albania based on biometric analysis and linear regression methods are made assumptions described by means of the linear function: $\mu \mathrm{Y}=\alpha+\beta \mathrm{X}+\varepsilon$, for expected tree ages. In this case we use Greek letters $\alpha$ and $\beta$, since we have a description of the related parametric (Ismaili et al., 1995; Mekuria et al., 1999). But in determining the age of the trees are considered the archaeological finds, the ages of civilizations, objects and references of affirmed historians. Because, according to mythology it is known that: ......In Illyria and Epirus, olive has been and remains... A Natural Foundation... for all the times... Element of the Landscape.... The best tree you give... good oil .... Who was born and raised, powerful and generous people....

\section{Materials and Methods}

The method followed for the exploration of old trees: In four ancient olive groves are organized exploratory missions to identify the oldest trees based on the information of the locals, over two basic terms: large trunk biometry and indigenous variety. The tabs are computerized, analyzed and inspected the selected trees.

Each individual is evaluated for the perimeter length, number of trunks, diameter in three, positions, the height of the tree and the volume of the crown, geographical position, the identity of the tree, the identity of the own. Traces and data for ancient olive oil processing. Olive germplasm distribution, culture situation, and history of old olive trees were analyzed, using olive database and external data from historical and archaeological archival documents. Photo shoots of tree and trunk in three positions have been made.

Neck biometric analysis of the trunk of each individual three positions diameter measurement, are analyzed, meanwhile the trunks and their position on the neck, periphery, center or homogeneous distribution.

The age method consisted in applying the equation over the perimeter curve terms, the annual growth of wood and the stability phase. Corrections to this method will continue with the application of carbon method in the future.

Data are processed and performed statistical analysis to determine the age and links of old trees with the mythology, culture and history of this country.

\section{Results and Discussion}

The olive ontogenetic: The ontogenetic cycle is the period from the formation of zygote to the physical loss of the genotype at the end of his life. Olive grows in thickness, renewed occasionally renewed, occasionally, but never dies.

When the olive is old, differentiates some seedlings in the perimeter area of the base of the trunk, that have the origin of the latent eye and thus is renewed for the time, but never dies of aging.

The new plant that replaces it is not another plant but a new self, a new expression of the same genotype. Olive can only die under the 
effect of frost, physical damage and burns from fires. The autochthonous olive property: Tirana has several main fireplaces of olive genetic diversity. The Tirana olive germplasm material represents a large and very important genetic patrimony, which includes native cultivated olives, and an abundant number of wild genotypes. It is under the influence of the Mediterranean Adriatic climate. The Adriatic Basin includes areas under the Adriatic's central part of the country and in geographic length over 40 degrees. This hearth is characterized by the white olive population, Oleaster and some of the most important soft varieties with genetic proximity (Barranco, et al., 2000); Multi century olive trees (thousands years old) are presented by individuals or small groups of individuals (from 5 to 20 olive trees/ha). Olive trees planted during XIV century period (evaluated 400-500 years old) are presented in blocks areas with 80-100 plants/ha.

Many genotypes are cultivated and have economic importance. Also, old cultivars are narrowly concentrated and continue to be cultivated as a result of large adaptation. The southern zone is characterized by greater density of resources, as for the number of genotypes and for the diffusion area. Wild olive resources result in a risk of extinction in many analyzed area, therefore they should be explored and studied.

\section{Inventory of old olive tree}

Every nation is characterized by language, earthly space, culture, wealth human, animal, and plant genetics. All these constitute a whole biodiversity, and olive is an important element of this biodiversity, for sustainability, diversity and functions that constitute the correlation with human generations.

There is a high relationship among Castles (pre-Illyrian/Illyrian Fortresses) and distribution of Old Olive Trees. The oldest olive trees are found near the castle before the Illyrian and Illyrian in Tujan, Preze, Ndroq and Persqop. They are near to them and serve as a landscape of old buildings. The olive tree contributes in shaping landscapes and has deep importance in the agro-economy, including the industrial economies based upon its by-products. The locals believe that they are the oldest trees in Albania. Various vessels, such as amphorae, barrels, pots, wooden bowls used by pre-Illyrians were discovered in Tirana, Preza, Persqop (Neolithic, Bronze Age).

About 300 trees are distinct, older, which evaluated more than 1.500 years and locals do not know the quality of the oil of these trees and the value to be taken from him. Though their age exceeds 1.500 years they annually produce fruit, regardless of age and level of maintenance. Following the election within 300 trees was discovered the oldest trees in their population. In this way, 30 trees are older, have an average age of 2,678 years, \pm Std Dev. 237 years. The age of individuals is determined according to a morph metric scientific method, based on many morphological and biological variables, such as: the perimeter value of the trunk neck, Thickness of wood $\mathrm{mm} /$ year and the stability phase (year) for Prob > P 0.95 .

The historical data have been taken into account for determining the age, archaeological data, the age of castles and opinion of the owners of the trees; with which reasonable corrections have been made

Individuals are composed of Tirana cultivars; "Bardhi Tiranes" (BT) and "Ziu Tiranes" (ZT), are typical autochthonous, distributed throughout on the central and northwestern region. Individuals; BR-1, DR-2, LI-1, MA-1, TU-3, TU-7, TU-1, resulted as the "ancestors" because their age is over 3000 years. The old 
trees are 200 to $400 \mathrm{~m}$ in height and according to estimates; these trees are thought to have been planted in the time of Piros of Epirus. So, this may be related to the olive origin in the eastern Mediterranean and especially in Greece. So the Spanish seeker also thinks that the olive tree was brought to the Iberian Peninsula by the Phoenicians and the Greeks of the south western Balkans.

The neck and the trunk are covered by a super-phelloderm stratum 15-25 mm thick. Cambium is a cellular plant tissue from which phloem, xylem, or cork grows by division, in secondary thickening and its function is to thicken the neck and the trunk.

The heart of the trunk has mechanical function and is made up of dead cells, rich in resin, tannin, mineral matter such as: calcium carbonate, silicon carbonate etc of protective function. The neck is volumetric, made up of lumps and numerous ovules which deform the outer surface considerably. The Neck's circumference had different values statistically caused by the influence of age, variety and quality of maintenance.

The mechanism of neck and trunk thickening was caused by the activity of cambium year per year, at different intervals of the annual cycle and progressively pursuant to the ontogenetic cycle. Sleeping buds in the neck reoccurred and differentiate new trunks from time to time and extend the physical and biological life and performance of the tree.

Growth in thickness is made continuously due to the differentiation of the new wood inside the ring and old wood outside the ring. The increase in cambium is correlated with the genetic profile, age and environment. The increase of cambium is different for each autochthonous variety. This coefficient is calculated for each variety and has resulted from 2-8 $\mathrm{mm} /$ year. It is a final phase when the neck of the trunk has no new differentiation, and this phase lasts 250-500 years, and we call it stages of stability (correction) $( \pm)$ which should be taken into account for the calculation of the age of each individual

In Figure 1, there are four old trees that are in Tirana. Seen two forms: (i) the pedestal of the trunk is hollow and multiple spaces and the tree stand on seven feet.

About 200 years the neck has not differentiated new trunks. About $80 \%$ of the trunk is rotten and the neck in some segments is disconnected. It's really a monument. (ii) The tree after the degradation of the mammoth trunk on the neck has differentiated three new trunks. The tree continues again by differentiating the new trunks. All old trees conform to one or the other individual described above (Fig. 2 and 3).

In Figure 4, it is seen that the average diameter of all individuals was $6.8 \mathrm{~m}$, but there are some individuals who have a dominant average compared to others. For example, TU3 has the highest value of the other individuals while the Brar-1 values are smaller the diameter.

The trunk neck according to morph metric analysis has different variables, in the dependencies of the position of the trunk on the neck; in peripheral, center or homogeneous distribution, or the trunk neck is separated from putrefaction, on the plane of the neck.

Through morph metric analysis of age, calculated with the interdependence of the perimeter value, the coefficient of annual timber growth and the index for correction; 30 individuals have average age 2678 years \pm 237 years. Seven individuals belong to two autochthonous varieties BT and UZ. 
Table.1 The oldest olive in the District of Tirana, geographic position, biometric indices and morphometric age

\begin{tabular}{|c|c|c|c|c|c|c|c|c|}
\hline \multirow{2}{*}{$\begin{array}{l}\text { Identit } \\
\mathbf{y}\end{array}$} & \multirow{2}{*}{$\begin{array}{l}\text { Locatio } \\
\text { n }\end{array}$} & \multirow{2}{*}{$\begin{array}{l}\text { Age } \pm \text { Std. } \\
\text { Dev }\end{array}$} & \multicolumn{3}{|c|}{ BIOMETRY } & \multicolumn{3}{|c|}{ GEOGRAPHICAL POSITION } \\
\hline & & & $\mathrm{P}$ & D & $\mathrm{H}$ & $\mathrm{N}$ & $\mathrm{E}$ & HG \\
\hline TU-2 & Tujan & $2800 \pm 320$ & 19.8 & 8.2 & 14 & 412242,53 & 19533,05 & 477 \\
\hline TU-1 & Tujan & $3000 \pm 300$ & 20.2 & 7.6 & 13 & 41223705 & 19532,08 & 487 \\
\hline TU-3 & Tujan & $3500 \pm 150$ & 22.4 & 11.2 & 12 & 412241,91 & 19531,01 & 466 \\
\hline TU-4 & Tujan & $2200 \pm 200$ & 13.3 & 5.8 & 14 & 412238,34 & 1953352 & 481 \\
\hline TU-5 & Tujan & $2800 \pm 250$ & 18.2 & 6.2 & 11 & 412243,37 & 195257,34 & 441 \\
\hline TU-6 & Tujan & $2000 \pm 200$ & 17 & 5.8 & 13 & 412243,03 & 195256,37 & 435 \\
\hline TU-7 & Tujan & $3000 \pm 250$ & 18.6 & 8.3 & 12 & 412240,58 & 195254,99 & 434 \\
\hline SHT-1 & Tufine & $2800 \pm 200$ & 17.2 & 6.2 & 10 & 41225,05 & 195221,99 & 279 \\
\hline SHT-2 & Gjerdh & $2800 \pm 200$ & 17.3 & 6.8 & 12 & 41226,00 & 195219,31 & 266 \\
\hline SHT-3 & Tufine & $2300 \pm 300$ & 14.5 & 6.0 & 13 & 41224,85 & 195219,28 & 270 \\
\hline$\overline{L I-1}$ & Linze & $3300 \pm 200$ & 22 & 8 & 14 & 412123,49 & 195255,49 & 312 \\
\hline LI-2 & Linze & $3000 \pm 200$ & 22.6 & 8.4 & 13 & 412118,22 & 195300,88 & 330 \\
\hline LI-3 & Linze & $2500 \pm 200$ & 16.4 & 6 & 10 & 412103,16 & 195302,56 & 354 \\
\hline LI-4 & Linze & $2800 \pm 250$ & 17 & 7 & 14 & 41210371 & 195304,92 & 331 \\
\hline B-1 & Bregas & $2900 \pm 300$ & 19.3 & 6.8 & 13 & 412048,67 & 195324,62 & 328 \\
\hline L-1 & Lanas & $3000 \pm 300$ & 22 & 7.1 & 10 & 412023,73 & 1953543,13 & 352 \\
\hline BR-1 & Preze & $3200 \pm 250$ & 22 & 8 & 15 & 412515,09 & 193929,37 & 155 \\
\hline BR-2 & Preze & $3000 \pm 250$ & 15.2 & 6.2 & 11 & 412515,58 & 193928,69 & 157 \\
\hline BR-3 & Preze & $2400 \pm 200$ & 15.5 & 5.9 & 12 & 412513,08 & 193931,37 & 143 \\
\hline BR-4 & Preze & $2200 \pm 300$ & 17 & 6.4 & 13 & 412522,49 & 193838,85 & 151 \\
\hline GR-1 & Grubll & $2150 \pm 200$ & 15 & 5.8 & 9 & 411622,20 & 193913,16 & 105 \\
\hline VA-1 & Varrosh & $2500 \pm 300$ & 16.3 & 6.8 & 13 & 411447,88 & 194007,08 & 267 \\
\hline VA-2 & Varrosh & $2200 \pm 200$ & 15.8 & 5.9 & 11 & 411439,12 & 193958,92 & 266 \\
\hline DR-1 & Durishti & $3000 \pm 100$ & 17.7 & 6 & 10 & 411348,52 & 195328,44 & 518 \\
\hline DR-2 & Durishti & $3500 \pm 300$ & 22.4 & 7.9 & 11 & 411389,94 & 195330,55 & 498 \\
\hline MA-1 & Majolle & $3500 \pm 300$ & 20.3 & 7.7 & 9 & 411353,31 & 195319,61 & 443 \\
\hline MA-2 & Majolle & $2500 \pm 200$ & 19.7 & 7.5 & 12 & 411353,84 & 195324,15 & 473 \\
\hline MA-3 & Majolle & $2000 \pm 200$ & 16.6 & 6.4 & 10 & 411352,29 & 195318,40 & 462 \\
\hline Brar-1 & Brar & $1500 \pm 250$ & 12 & 4.3 & 10 & 412345,79 & 195214,52 & 350 \\
\hline LU-H & Lunder & $2000 \pm 250$ & 12 & 4.6 & 9 & 411722,78 & 195255,78 & 226 \\
\hline
\end{tabular}

D- Diameter for 3 positions; P-Perimeter; H- height of the tree; HG- Hight; N- Geographic length; E- latitude. 
Fig.1 Four old olive trees in the province of Tirana the data presented in Table 1
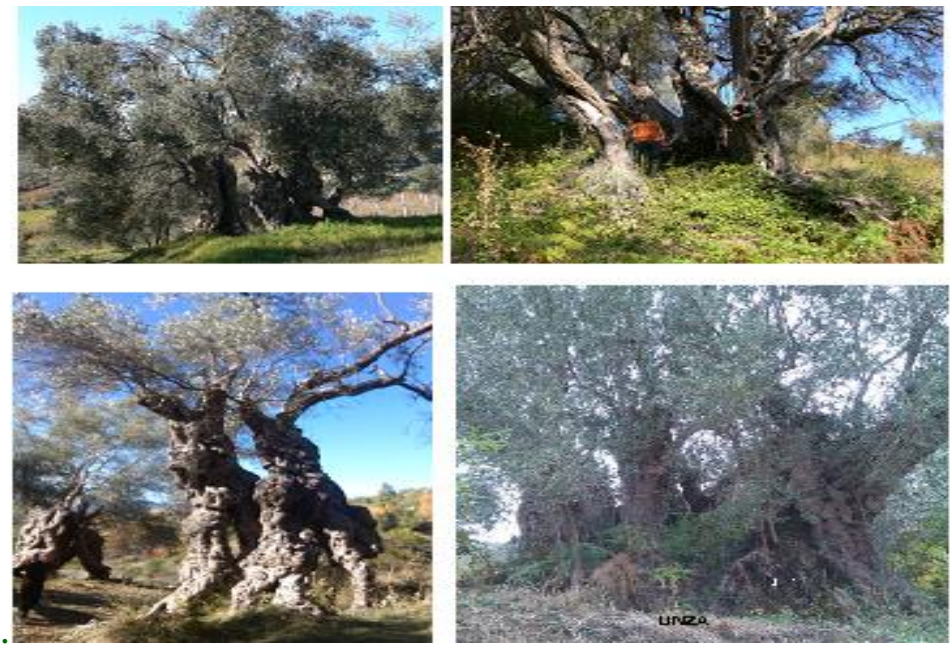

Fig.2 Graphical representation of the average three-dimensional size of the neck diameters

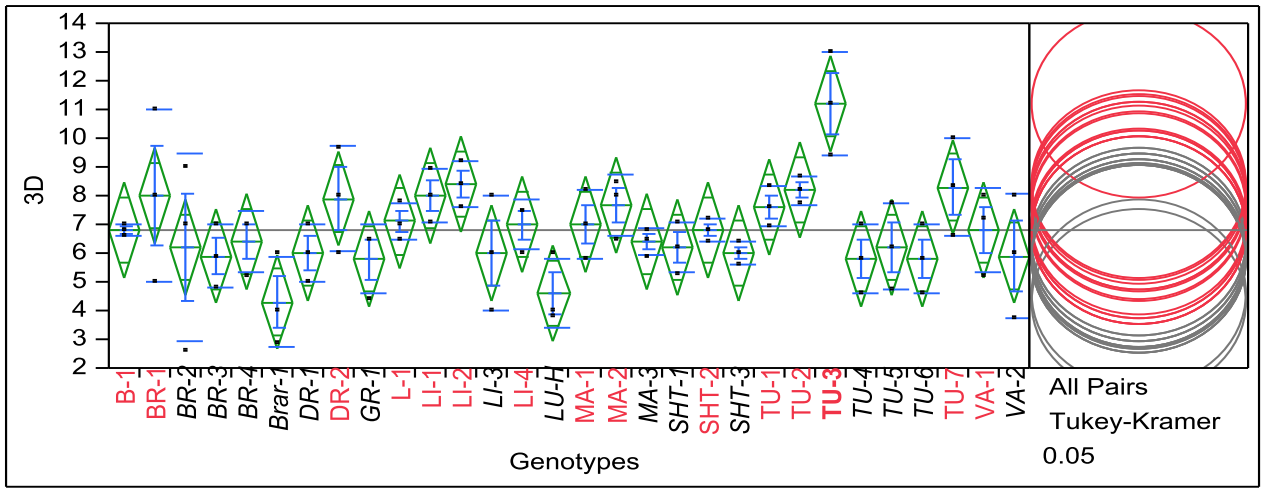

Fig.3 (Left) Statistical link between neck circumference of the trunk and the age of olive genotypes

Fig.4 (Right) Age of olive genotypes based on the morph metric method: the perimeter of the trunk neck, wood thickness and stability phase
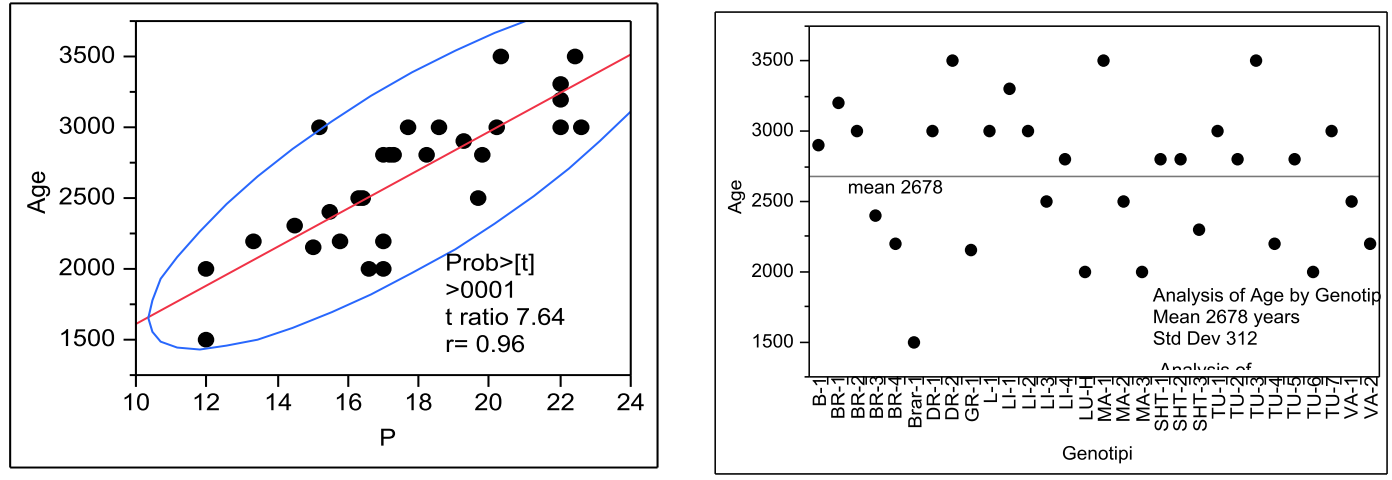
Among them, seven trees were evaluated with the old in this region, possibly the champion for Albania. The trees are: BR-1, DR-2, LI-1, MA-1, TU-3, TU-7 and TU-1. The age data analysis has shown a very strong connection to the perimeter $(\mathrm{P})$ with, $\mathrm{r}=96 \%$. Overall, it has been shown that increasing the value of the perimeter increases the age value. Deviation of \pm age is 237 years. While the amplitude of 100 to 350 years and the frequencies are different.

According to the Figure 4, the relationship between the two indices has occurred to each individual because all correlation values are within the plot per prob $>[\mathrm{t}]<00001 *$.

The frequency of these old trees in this province is $3-4 \%$ and there is a tendency for decreasing, and the causes of this phenomenon are peoples.

In each case of analysis, values of individual observations do not fall exactly on the regression line, but they form a set of points that are placed around the regression line. This distribution of points is usually a natural variation of individual observations, caused by the genetic and environmental characteristics as well as measurement errors.

If, these olive trees could talk, they would tell a lot... first, they would show who made the sapling, afterwards, who has planted them? The current owner does not know any age and history of their life. Therefore, according to our estimation, these trees have hailed for 2-3 thousand years, their human contemporaries. They waited and followed more than 100 human generations, they have survived in this natural environment and have formed some characteristics ecosystems and durable.

The castles which possessed near the old olive trees they represent a traditionally valued source of healthy nourishment historically and a symbol of joys and victories, rituals, and popular culture and tradition.

Olive older individuals have varietal population and are in the company of many wild individuals of subspecies Sylvester's and oleaster, and prove the hypothesis that this country may be a country of origin. Regarding the judgment of many scientists, the Mediterranean basin up to the $39^{\circ}$ belt, is the leading country of origin of olive.

This research has put in practice for the first time, some morphological indices and statistical models to evaluate the growth of the trunk and the neck, as well as the age of the tree. As the neck is the main regenerating organ, analysis on its morphology enables a higher level of accuracy in determining the age.

It is very significant the fact the great number of Old olive trees is situated near or relatively near the castles that were at the same time the centers of antique civilization.

Only a part of the objects found have the conditions for promotion because they are an exclusive testimony of ancient cultures of the country.

\section{References}

Bae, K. and Derek, D., 2008. A method for automated registration of unorganised point clouds. ISPRS Journal of Photogrammetry and Remote Sensing, 63(1), 36-54.

Barranco, D., Rallo L., 2000. Olive cultivars in Spain. Hortech, 10 (1): 107-110.

Bruno F., Bruno S., De Sensi G., Luchi M., Mancuso S., Muzzupappa M., 2010. From 3D reconstruction to virtual reality: A complete methodology, Journal of Cultural Heritage, 11, 42-49.

Cantini C. Panicucci M. - Managing of a 
traditional olive orchard by time saving biennial pruning. Acta Horticulturae, 586, 361-364, 2002.

Ismaili, H., Çeloaliaj Q. 1995. Alcuni aspetti dell olivicoltura albanese. Atti Convegno "L’Olivicoltura Mediterranea", Ist. Sper. Oliv., Rende (Cs), Italia 26-28 Geennaio., 85 - 92.

Loukas, M. and C.B. Krimbas, 1983. History of olive cultivars based on their genetic distances. J Hort Sci., 58:121-127.

Lovell, J.L., Jupp, D.L.B., Newnham, G.J., Culvenor, D.S., 2011. Measuring tree stem diameters using intensity profiles from ground-based scanning lidar from a fixed viewpoint. ISPRS Journal of Photogrammetry and Remote Sensing., 66, (1), 46-55.

Mekuria, G.T., G.G. Collins and M. Sedgley, 1999. Genetic variability between different accessions of some common commercial olive cultivars. J Hort Sci and Biotechnol., 74: 309-314.

Osmani, R., 1993. Aspetti del Germoplasma
Olivicolo Albanese. Frutticoltura, 3:5963. 112

Remondino F., Girardi S., Rizzi A., Gonzo L., 2009. 3D modeling of complex and detailed cultural heritage using multiresolution data, Journal on Computing and Cultural Heritage (JOCCH), v.2 n.1, p.1-20.

Riley, F., 2002. Olive oil production on Bronze Age Crete: Nutritional Properties, processing methods and storage life of Minoan olive oil. Oxford Journal of Archeology, 21(1), 63-75.

Scopigno R., Callieri M., Cignoni P., Corsini M., Dellepiane M., Ponchio F., Ranzuglia G., 2011. 3D models for Cultural Heritage: beyond plain visualization, IEEE Computer, 44, (7), 48-55.

Trujillo, I., L. Rallo, E.A., Carbonell and M.J. Asins, 1990. Isoenzimatic variability of olive cultivars according to their origin. Acta Hort., 286: 137-139.

\section{How to cite this article:}

Hairi Ismaili. 2018. Analysis of Some Very Old Olive Tree. Int.J.Curr.Microbiol.App.Sci. 7(01): 2305-2312. doi: https://doi.org/10.20546/ijcmas.2018.701.278 